\title{
Association of Sleep Paralysis with PTSD Symptoms, Pathological Worry and Perceived Stress
}

\author{
Azal Ikhlaq ${ }^{1 *}$, Hunniya BER ${ }^{1}$, Imtiaz Bashir ${ }^{1}$, Farhat Ijaz ${ }^{2}$ and Rana Khurram Aftab ${ }^{3}$ \\ ${ }^{1}$ Medical Student, CMH Lahore Medical College, Pakistan \\ ${ }^{2}$ Associate Professor Physiology, CMH Lahore Medical College, Pakistan \\ ${ }^{3}$ Punjab institute of Cardiology, Lahore, Pakistan
}

Submission: February 17, 2021; Published: March 08, 2021

*Corresponding author: Azal Ikhlaq, Medical Student, CMH Lahore Medical College, Pakistan

\begin{abstract}
In the current study, we inspected the correlation between Sleep Paralysis and anxiety symptoms among undergraduate medical students of Pakistan. It was a questionnaire based cross-sectional study. Pre-tested, pre-designed questionnaires were administered to 100 participants and any association between sleep paralysis and PTSD symptoms, Perceived Stress, or Pathological worry was found. There was a positive correlation between Experience of Sleep Paralysis and PTSD Symptoms ( $\mathrm{d}=0.319$ and $\mathrm{p}=0.001$ ), Pathological Worry and Sleep Paralysis ( $\mathrm{p}=0.005$ and $d=0.270$ ), and Perceived Stress and Sleep Paralysis ( $p<0.001$ and $r=-0.394)$. Pakistani population particularly medical undergraduates have a high prevalence (52.8\%) of frequent experiences of sleep paralysis. Also, the high rate of occurrence among the females than males and higher rates in adolescents are particularly of concern. Statistically significant correlation between sleep paralysis and PTSD symptoms, PSS value, and PSWQ score is found. Efforts should be made to remove the factors responsible for anxiety and distress among masses.
\end{abstract}

Keywords: Sleep paralysis; PTSD; Stress; Anxiety; Hallucinations

Abbreviation: SP: Sleep Paralysis; ISP: Isolated Sleep Paralysis; PTSD: Post-Traumatic Stress Disorder; STAI: State Trait Anxiety Inventory; PSWQ: Penn-State Worry Questionnaire; PSS: Perceived Stress Scale; USEQ: Unusual Sleep Experience Questionnaire; PCL-C: PTSD ChecklistCivilian Version

\section{Introduction}

Sleep paralysis (SP) is a queer phenomenon which might be portrayed as "brief episodes of powerlessness, inability to talk and even to open one's eyes on arousing from sleep [1]. Sleep paralysis has typically been depicted as far as its relationship with narcolepsy. Surely, it is thought of as one of the segments of the narcolepsy quadruplicate (i.e., sleep attack, cataplexy, sleep paralysis, and hypnagogic hallucinations). In spite of the fact that rest loss of motion is oftentimes connected with other narcoleptic conditions, it likewise happens autonomously, without rest assault or cataplexy, in any case sound people [2]. Various societies clarify the loss of motion and fantasies in an unexpected way. Otherworldly records of the daydreamed gatecrasher are normal [3]. SP is referred as "Old Hag" [4] in Newfoundland, and as kanashibari (i.e., demons [5]) in Japan, "ghost oppression" in China [6]; "the ghost pushes you down" [7] among Cambodians; and in the United States, sometimes space alien abduction [8].
After getting to following causes were discovered, Isolated Sleep Paralysis (ISP) encounters are just feebly connected with an earlier determination of mental issue, [2] detected presence during ISP is related specially with ISP misery, and [3] ISP trouble is related with broken social symbolism. An overall inclination to emotional misery may impact the trouble related with ISP encounters; excessively latent social symbolism may, thusly, be embroiled in this influence trouble impact [9]. The term fearful isolated sleep paralysis has been used by some authors to indicate cases where episodes are causing clinically significant fear and/or distress [10]. The factors found for sleep paralysis include posttraumatic stress problem (PTSD), anxiety sensitivity, regularly conceptualized as a dread of the results of intellectual and physical appearances of uneasiness, is raised in individuals with SP and, as in panic disorder, has been speculated to be an etiological factor [11]. 
In the current study, we inspected the correlation between SP and anxiety symptoms among undergraduate medical students of Pakistan. Finding a correlation between SP and anxiety symptoms might help prevent this awful experience as indicated in other studies [10]. To our knowledge, no such study has been conducted in Pakistan.

\section{Methodology}

After taking ethical approval from host institute, a questionnaire based cross-sectional study was carried out at $\mathrm{CMH}$ LMC, consisting of 100 undergraduate medical students. Informed consent was taken. The questionnaire consisted of demographic information, the questionnaire on sleep paralysis and scales for post-traumatic stress disorder (PTSD), State Trait Anxiety Inventory (STAI), Penn-State Worry Questionnaire (PSWQ) and Perceived Stress Scale (PSS). Assessment of Sleep Paralysis; its presence, features, and frequency, was done using Unusual Sleep Experience Questionnaire (USEQ) [12].

PTSD Checklist- Civilian Version (PCL-C) was used to assess PTSD. PCL consists of 17 questions with rating on a 5-pointLikert scale. The PSWQ consisting of 16 items on a 5-point-Likert scale was used to assess pathological worry in the participants. Perceived Stress Scale (PSS) was used to analyze the stress level of the participants. The information gathered was analyzed using SPSS version 25. Quantitative factors were recorded in means and standard deviations. Qualitative factors were given as frequency and percentages. Pearson correlation was applied. A p value $\leq 0.05$ was considered significant.

\section{Results}

$52.8 \%$ of participants reported at least one lifetime episode of SP (20.8\% with 1-4 lifetime episodes, $20 \%$ with more than 4 episodes in the previous year) (Table 1). Among those who had experienced SP, 55.3\% reported hallucinations during SP and 76\% reported to be in a state unable to move during the experience (Table 2).

Table 1: General Characteristics of the study population.

\begin{tabular}{|c|c|}
\hline Attributes & $\begin{array}{c}\text { Respondents (n=100) } \\
\text { No. (\%) }\end{array}$ \\
\hline Gender & $23.40 \%$ \\
\hline Male & $76.60 \%$ \\
\hline Female & \\
\hline Age & $47.10 \%$ \\
\hline Cluster 1 (18-21 years) & $66.10 \%$ \\
\hline Cluster 2 (22-25 years) & \\
\hline Discipline & $86.80 \%$ \\
\hline MBBS & $5.20 \%$ \\
\hline BDS & \\
\hline
\end{tabular}

\begin{tabular}{|c|c|}
\hline Allied Health Sciences & $11.20 \%$ \\
\hline Year of study & $26 \%$ \\
\hline 1st Year & $58.50 \%$ \\
\hline 2nd Year & $15.10 \%$ \\
\hline 3rd Year & $6.80 \%$ \\
\hline 4th Year & $6.50 \%$ \\
\hline 5th Year & \\
\hline
\end{tabular}

Table 2: Rates of different events related to Sleep Paralysis among the participants.

\begin{tabular}{|c|c|}
\hline Events During Sleep Paralysis & Rates in Individuals \\
\hline \multirow{2}{*}{ One lifetime episode of sleep paralysis } & $52.8 \%$ yes \\
\cline { 2 - 2 } & $47.2 \%$ no \\
\hline Unable to move & $76.65 \%$ \\
\hline Unable to speak & $55.30 \%$ \\
\hline Terror or Anxiety & $34 \%$ \\
\hline \multirow{2}{*}{$\begin{array}{c}\text { Hypnogogic or hypnopompic hallucina- } \\
\text { tions (visual, auditory and tactile) }\end{array}$} & $55.30 \%$ \\
\hline \multirow{2}{*}{ Age when experienced SP } & Below 14 years $12.9 \%$ \\
\cline { 2 - 2 } & $15-17$ years $30 \%$ \\
\cline { 2 - 2 } & $18-20$ years $41.2 \%$ \\
\hline
\end{tabular}

\section{Correlations}

SP and PTSD the individuals who had experienced at least one life-time episode of sleep paralysis had significantly high values for PCL-C as compared to the non-experiencers Pearson values being $d=-0.319$ and $p=0.001$. SP and PSS the $p<0.001$ and $r=-0.394$ shows that SP and PSS have positive relation and the recurrent attacks of SP. SP and PSWQ the frequency of occurring in $\mathrm{SP}+$ individuals and those having high scores of PSWQ also show considerable association of $\mathrm{p}=0.005$ and $d=0.270$ (Table 3).

Table 3: Value of Pearson Correlations and P-values.

\begin{tabular}{|c|c|c|}
\hline & Correlation & p-value \\
\hline SP and PTSD & 0.319 & 0.001 \\
\hline SP and PSS & 0.394 & 0.001 \\
\hline SP and PSWQ & 0.27 & 0.005 \\
\hline
\end{tabular}

\section{Discussion}

The sleep paralysis has been found to be occurring in the normal individuals [10] and leaving with them a lot of worry and fear leading to disturbed life and diverted attention of individuals in their daily life, so it is of much concern in psychiatric circles these days and might be of concern to the general public when the awareness will arise about it.

The results showed that more than half approximately $52.8 \%$ reported to be sleep paralysis experiencers among the normal 
individuals. It affirms the idea that of SP in normal individuals which is an alarming situation because of its effects on sleep cycles and general mental health of the individual and among them almost 20\% reported to have experienced SP more than 4 times during the past year. This high frequency of sleep paralysis affirms the idea of recurring isolated sleep paralysis as shown by the previous research [13] and this is an alarming situation as the more specific "recurrent isolated sleep paralysis" is widely mistaken as sleep-wake disorder by non-sleep specialists [11].

The events experienced during isolated sleep paralysis are also quite similar in terms of hypnagogic and hypnopompic hallucinations and inability to move which have been reported by $76 \%$ of the individuals which is depicted in terms of visual hallucinations by Hinton and colleagues showing that approximately $90 \%$ of highly traumatized Cambodian Refugees have visual hallucinations during an episode of SP [13]. With regard to the demographic profile, it has been observed that sleep paralysis is more among females than males. The higher rates of occurrence among females then males seen in current study may be due to the high stress levels in females than in males [13] as this sample is taken from Pakistani population, so the social challenges of females are far more than males leading to their high stress levels and also because a direct relation has been found between sleep paralysis and PSS in the current study.

As far as the age group is concerned the higher rates of sleep paralysis is observed in the 18 to 20 years as depicted that during adolescence, sleep paralysis with hallucinations is more frequent among adolescents which confirms high stress levels among young people [14]. There is a positive relation between SP and PTSD, trait anxiety and worry which is consistent with previous literature [11]. Indeed, as noted SP has been linked with anxiety and trauma. This link has been found in association with trauma and anxiety, this association has predominantly been found in persons who have undergone trauma like event [15].

Additionally, stress over the sleep paralysis indications demolishes stress and stress deteriorates PTSD side effects by prompting elevated danger mode and hyper-vigilance to danger, expanded crabbiness and conceivably panic like autonomic feelings of excitement and trauma reviews [16]. So, this vicious cycle of worry, PTSD and ultimately sleep paralysis and panic attacks [17] causing the condition to get worsened which is consistent with previous literature. This also advocates the possible cause of positive relationship between SP and PSWQ and PSS, but independent relation is also present which is shown by the current study that increased PSWQ and PSS levels induce more episodes of SP.

\section{Conclusion}

This study is first to describe a correlation among SP and trauma and anxiety symptoms in Pakistan. Pakistani population particularly medical undergraduates have a high prevalence of frequent experiences of sleep paralysis. Also, the high rate of occurrence among the females than males and higher rates in adolescents are particularly of concern. Statistically significant correlation between sleep paralysis and PTSD symptoms, PSS value, and PSWQ score is found. So, efforts should be made to remove the factors responsible for anxiety and distress among masses.

\section{References}

1. Goode GB (1962) Sleep paralysis. Arch Neurol 6(3): 228-234.

2. Fukuda K, Miyasita A, Inugami M, Ishihara K (1987) High prevalence of isolated sleep paralysis: Kanashibari phenomenon in Japan. Sleep 10(3): 279-286.

3. Jalal B, Ramachandran VS (2014) Sleep paralysis and "the bedroom intruder": the role of the right superior parietal, phantom pain and body image projection. Med Hypotheses 83(6): 755-757.

4. Hufford JD (1982) The terror that comes in the night: An experiencecentered study of supernatural assault traditions. University of Pennsylvania Press.

5. Arikawa H, Templer DI, Brown R, Cannon WG, Thomas Dodson S (1999) The structure and correlates of kanashibari. J Psychol 133(4): 369-375.

6. Wing YK, Lee ST, Chen CN (1994) Sleep paralysis in Chinese: ghost oppression phenomenon in Hong Kong. Sleep 17 (7): 609-613.

7. Hinton DE, Pich V, Chhean D, Pollack MH (2005) The ghost pushes you down': sleep paralysis-type panic attacks in a Khmer refugee population. Transcult Psychiatry 42(1): 46-77.

8. Mc Nally RJ, Clancy SA (2005) Sleep paralysis, sexual abuse, and space alien abduction. Transcult Psychiatry 42(1): 113-122.

9. Solomonova E, Nielsen T, Stenstrom P, Simard V, Frantova E, et al. (2008) Sensed presence as a correlate of sleep paralysis distress, social anxiety and waking state social imagery. Conscious Cognition 17(1): 49-63.

10. Sharpless BA, Doghramji K (2015) Sleep paralysis: historical, psychological, and medical perspectives. Oxford University Press.

11. Sharpless BA (2016) A clinician's guide to recurrent isolated sleep paralysis. Neuropsychiatr Dis Treat 12: 1761-1767.

12. Paradis C, Friedman S, Hinton DE, Mc Nally RJ, Solomon LZ, et al. (2009) The assessment of the phenomenology of sleep paralysis: the Unusual Sleep Experiences Questionnaire (USEQ). CNS Neurosci Ther15(3): 220-226.

13. Levin M (1933) The Pathogenesis of Narcolepsy, with a Consideration of Sleep-Paralysis and Localized Sleep. J Neurol Psychopathol 14(53): $1-14$.

14. Ohaeri JU, Odejide AO, Ikuesan BA, Adeyemi JD (1989) The pattern of isolated sleep paralysis among Nigerian medical students. J Natl Med Assoc 81(7): 805-808.

15. Solomonova E, Nielsen T, Stenstrom P, Simard V, Frantova E, et al (2008) Sensed presence as a correlate of sleep paralysis distress, social anxiety and waking state social imagery. Conscious Cogn 17(1): 49-63.

16. Hinton DE, Nickerson A, Bryant RA (2011) Worry, worry attacks, and PTSD among Cambodian refugees: A path analysis investigation. Soc Sci Med 72(11): 1817-1825.

17. Jalal B, Simons RJ, Jalal B, Hinton DE (2014) Explanations of sleep paralysis among Egyptian college students and the general population in Egypt and Denmark. Transcult Psychiatry 51(2): 158-175. 
(C) This work is licensed under Creative (1) Commons Attribution 4.0 License DOI: 10.19080/IJOPRS.2021.04.555648
Your next submission with Juniper Publishers will reach you the below assets

- Quality Editorial service

- Swift Peer Review

- Reprints availability

- E-prints Service

- Manuscript Podcast for convenient understanding

- Global attainment for your research

- Manuscript accessibility in different formats ( Pdf, E-pub, Full Text, Audio)

- Unceasing customer service

Track the below URL for one-step submission https://juniperpublishers.com/online-submission.php 